\title{
Laser printing of micro-electronic communication systems for smart implants applications
}

\author{
C.G. Moura ${ }^{a, *}$, O. Carvalho ${ }^{a}$, V.H. Magalhães ${ }^{a}$, R.S.F. Pereira ${ }^{\text {, }}$, M.F. Cerqueira ${ }^{b, c}$, \\ L.M.V. Gonçalves ${ }^{\mathrm{a}}$, R.M. Nascimento ${ }^{\mathrm{d}}$, F.S. Silva ${ }^{\mathrm{a}}$ \\ a CMEMS-UMinho, Universidade do Minho, Campus de Azurém, 4800-058 Guimarães, Portugal \\ ${ }^{\mathrm{b}}$ Centro de Física, Universidade do Minho, Campus de Gualtar, 4710-057 Braga, Portugal \\ ${ }^{c}$ Internationaliberian Nanotechnology Laboratory (INL), 4715 Braga, Portugal \\ ${ }^{\mathrm{d}}$ Materials Science and Engineering Post-Graduate Program, UFRN, 59078-970 Natal, Brazil \\ ${ }^{\mathrm{e}}$ Federal Institute of Santa Catarina, IFSC, 88020-300 Florianópolis-SC, Brazil
}

\section{H I G H L I G H T S}

- A hybrid approach for printing micro-wires on titanium substrate were presented

- The resistivity of the micro-wires was assessed via experimental and computational.

- A comparative study between laser and anodizing for insulation layer was performed.

- Laser technology was successfully used in additive and subtractive approaches.

\section{A R T I C L E I N F O}

\section{Keywords:}

Nd:YAG laser

Laser surface modification

Laser oxidation

Laser sintering

Ti6Al4V titanium alloy

Implants

\begin{abstract}
A B S T R A C T
Endow the implant with intrinsic communication system between sensors and actuators or between implant and patient is a key factor for its long-term success. The capacity of early diagnosis of failures and the ability to remedy them are necessary to minimize expensive complications and reducing revision procedures. Ti6Al4V is the most used titanium alloy for implant's fabrication. In this sense, this work presents a promising approach to print communication systems by using laser technology, aiming integrate the smart components on titanium implants. Laser has been employed as a versatile tool to modify the surface in different ways, such as texturing, oxidizing and sintering. Silver wires have been printed on Ti6Al4V surface in order to conduct electrical current. To minimize current loss for the substrate, titanium oxide layer has been produced by different methods (laser and anodization). Laser sintering (LS) has been also compared to a conventional method (Hot-pressing- HP) to consolidate the silver powder into the cavities. In comparison to the conventional techniques, laser demonstrated to be a competitive approach to oxidizing the surface and also for consolidating the micro-wires on Ti6Al4V surface. Consequently, the micro-wires printed by laser approach presented satisfactory results in terms of electrical resistance, actuating as the conductor path for electrical current, with values of $0.0131 \Omega$, which is similar to the resistance of the wire printed in an insulator substrate.
\end{abstract}

\section{Introduction}

Commercial pure titanium and titanium alloy (Ti6Al4V) are still the elected materials in the fabrication of implants, due to their great biocompatibility and mechanical properties [1-3]. Although it has a high success rate of these implants, some failures are still arising, leading to an early revision surgery and implant replacement. Many studies have been undertaken to improve the titanium implants properties, such as osseointegration, bioactivity, surface and the material itself [4-7]. However, the early diagnosis of failures and the ability to remedy them are also key points to increase the lifetime of the implants, minimizing expensive complications and reducing revision procedures [8].

In this context, smart implants have been extensively explored by scientific community, in order to develop an implant with several capacities. Smart implants are implantable devices that provide not only

\footnotetext{
* Corresponding author at: CMEMS-Uminho, Universidade do Minho, Campus de Azurém, 4800-058 Guimarães, Portugal.

E-mail address: id5983@alunos.uminho.pt (C.G. Moura).
} 
therapeutic benefits but also diagnostic capabilities [9]. Smart implants have been applied in knee arthroplasty, hip arthroplasty, fracture fixation and others. To date, they have been used to measure several physical parameters from inside the body, such as pressure, force, strain, displacement and temperature [9]. The data prevenient from the smart implants have led to the refinement and improvement of design and implant technology. Although the technology underlying smart implants, including sensing, power transfer, energy storage and wireless communications, has grown in the last decades, there are still challenges to be overcome to bring smart implants into daily clinical, mainly because the actual sensors technology requires significant modification of the implants design.

Recent advances have been shown some solutions regarding accommodation of smart components along to the implant. However, the creation of huge cavities to adapt these components, besides altering the implant's design and its properties, may compromise its long-term performance $[10,11]$. In this sense, the smart implants concept combined with 3D printing technology with multi-material approaches, is a promising solution to overcome the recurring challenge of this area. These technologies combination allows to print, layer by layer, implants where a communication system (comprised by sensors and actuators materials) may be integrated, giving rise to a component with intrinsic capacities to sense or actuate. This potential application is described in details in our previous work [12] and the overall idea is presented in Fig. 1.

On the basis of the foregoing, this work aims at developing an alternative approach for printing integrated communication system on implants, in order to endow the implant with intrinsic capacities. Laser technology was applied as a versatile tool, whether for prepare the surface of Ti6Al4V in a subtractive way, by creating the micro-cavities, or for print smart components, in an additively way. Besides, laser was also applied for thermal-chemical treatments, by creating an oxide layer to act as electrical insulation of communication wires.

\section{Experimental details}

\subsection{Micro-cavities production}

A Nd:YAG laser (OEM Plus, working in wavelength of $1064 \mathrm{~nm}$ and $6 \mathrm{~W}$ of maximum power) was used to produce the micro-cavities on the surface of a $2 \mathrm{~mm}$ thick Ti6Al4V titanium alloy target. To create the micro-cavities (with $250 \mu \mathrm{m}$ of average width), a strategic design was used, in which overlapping lines with different wobble amplitudes were built by laser, aiming to produce a cavity with more rounded shape (Fig. 2). A sequence of 10 wobbles lines with different widths (from 25 to $250 \mu \mathrm{m}$ ) overlapped was performed, where the scanning speed has

\section{Hybrid Process for communication svstem manufacturing}

\section{Component building}

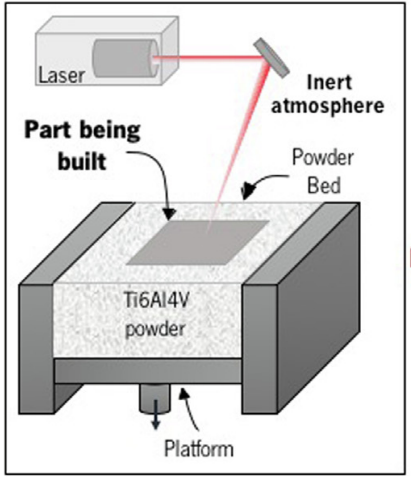

\section{Micro-channel production}

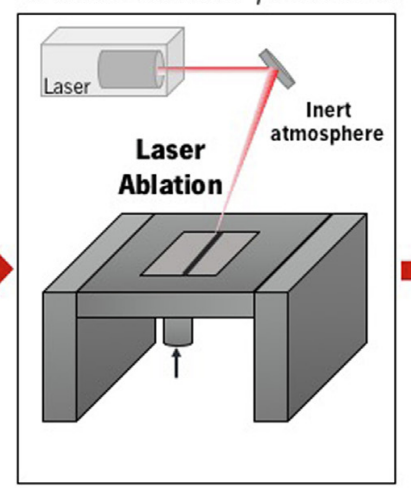

\section{Surface oxidation}

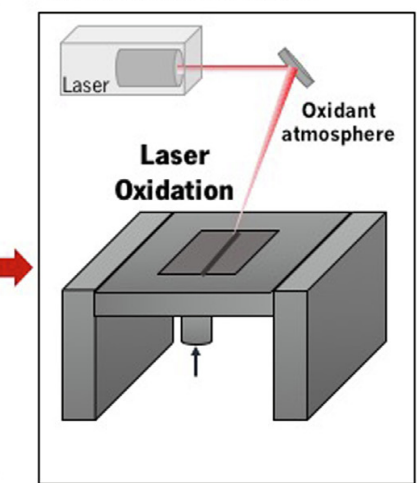

5. Building of the following layers

\section{Micro-wire printing}

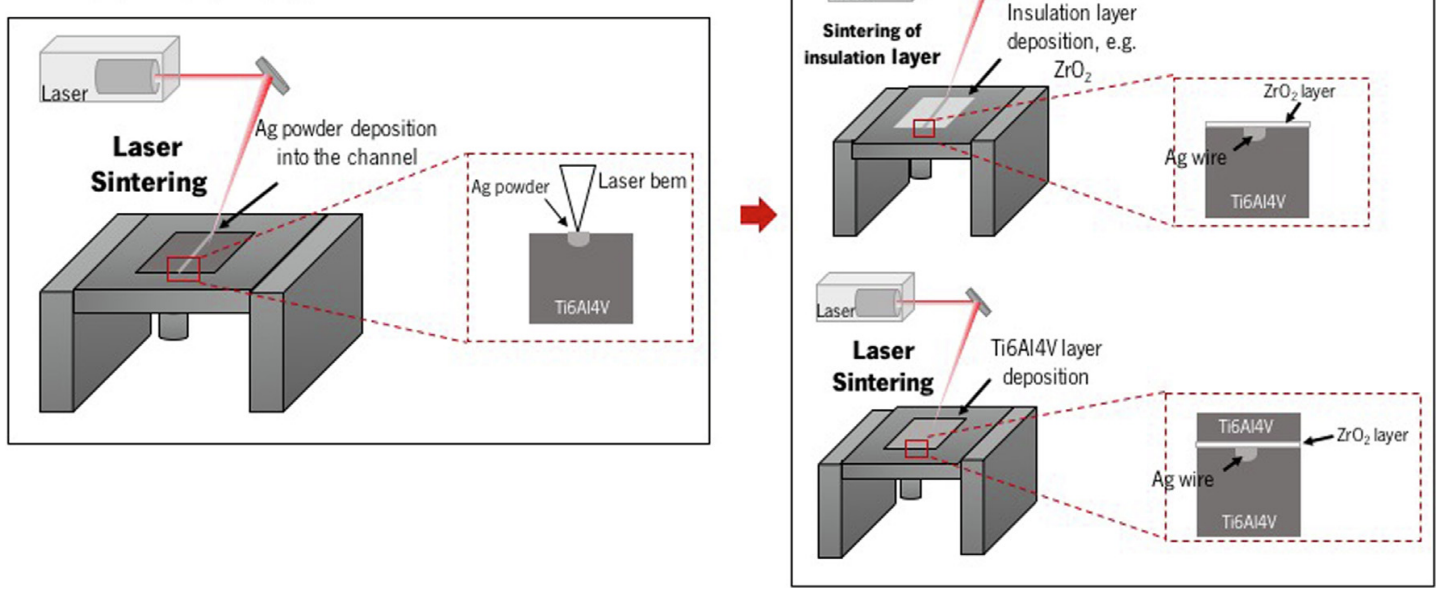

Fig. 1. Scheme of the communication system production steps by laser additive manufacturing. 


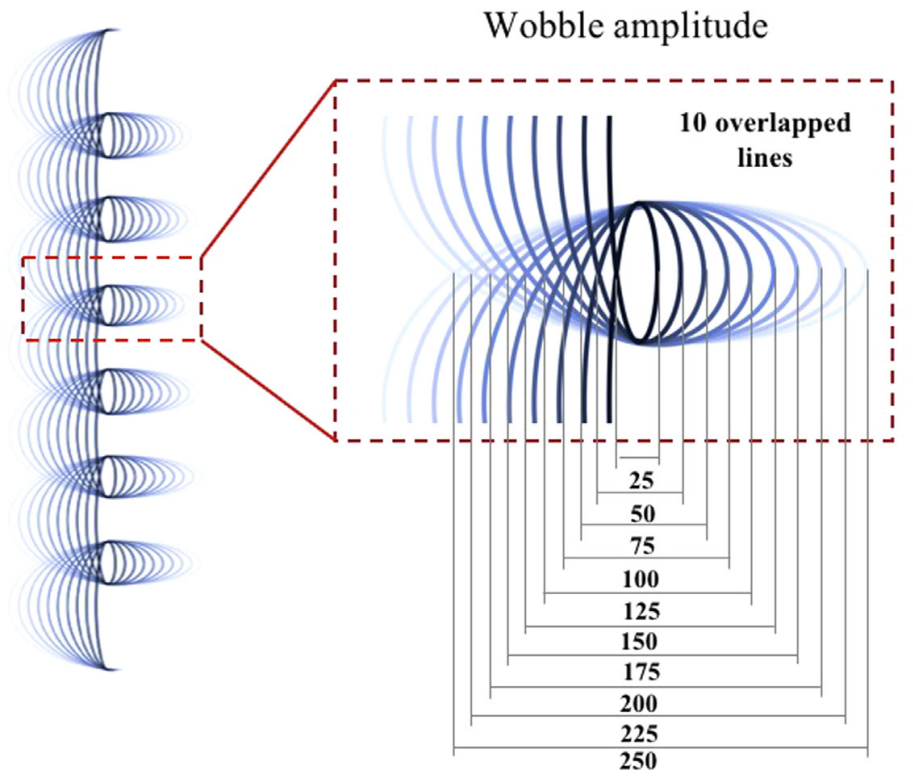

\begin{tabular}{c|c}
$\begin{array}{c}\text { Wobble } \\
\text { amplitude } \\
(\mu \mathrm{m})\end{array}$ & $\begin{array}{c}\text { Scanning } \\
\text { speed } \\
(\mathrm{mm} / \mathrm{s})\end{array}$ \\
\hline 25 & 20 \\
\hline 50 & 18 \\
\hline 75 & 16 \\
\hline 100 & 14 \\
\hline 125 & 12 \\
\hline 150 & 10 \\
\hline 175 & 8 \\
\hline 200 & 6 \\
\hline 225 & 4 \\
\hline 250 & 2 \\
\hline
\end{tabular}

Fig. 2. Schematic drawing of the micro-cavity build produced by the laser.

been changed in each one (from 20 to $2 \mathrm{~mm} / \mathrm{s}$ ), in order to better distribute the laser energy along the cavity. While the wobble amplitude increased, the scanning speed has decreased aiming to machine more evenly from the inside out of the micro-cavity. The laser is pulsed, and the spot has a diameter of $3 \mu \mathrm{m}$, then each laser textured line consists in a sequence of several pulses with an overlap area.

\subsection{Surface oxidation}

The anodic oxidation, illustrated in Fig. 3b, was carried out in potentiostatic mode at room temperature by using $0.4 \mathrm{M} \mathrm{H}_{3} \mathrm{PO}_{4}$ as electrolyte. A rectangular graphite plate was used as the counter-electrode. The exposure area was $8 \mathrm{~mm}$ in diameter for all the samples. Two voltages were tested: $20 \mathrm{~V}$ and $120 \mathrm{~V}$ for $1 \mathrm{~min}$, in order to evaluate the effect of the thickness in the insulation performance of the film. This procedure results in formation of a film, having purple color for $20 \mathrm{~V}$ and green color for $120 \mathrm{~V}$ condition.
For the film oxidation (stage 3 of Fig. 1), the same Nd:YAG (1064 nm of wavelength) laser was used to make a thin texture on the surface, in order to obtain the oxidized layer. A laser energy of $0.094 \mathrm{~J} /$ $\mathrm{mm}$ was used to irradiate all the surface.

The morphology of the oxidized films was analyzed using scanning electron microscope (SEM - FEI Nova 200) and the phase composition was analyzed by X-ray diffraction (XRD- Bruker D8 Discover) using a $\mathrm{CuK} \alpha$ radiation at a grazing angle of $1^{\circ}$. The thickness of the anodized films was measured by an atomic force microscope (AFM - Bruker), using a scan rate of $0.7 \mathrm{~Hz}$ at room temperature in tapping in air mode. In this regard, two samples were prepared: first, they were carefully polished till mirror finishing. Then, the half of the surface was then covered by a piece of DUPONT ${ }^{\mathrm{TM}}$ KAPTON $^{\circledR}$ tape (polyamide film resistant to acid), in order to obtain two zones: the anodized zone and the non-anodized zone.

\section{b) SURFACE OXIDATION}

a)

\section{MICRO-CHANNEL PRODUCTION}

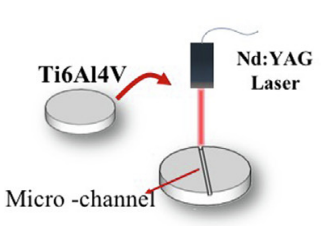

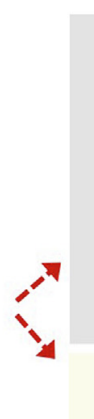

\section{Nd:YAG Laser}

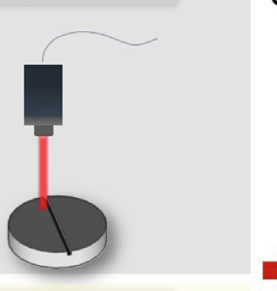

Anodization

DC Power Supply

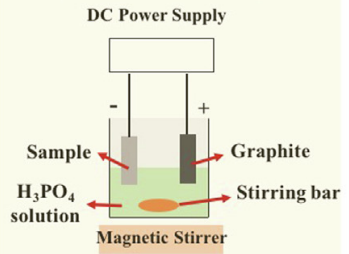

c)

SILVER POWDER DEPOSITION

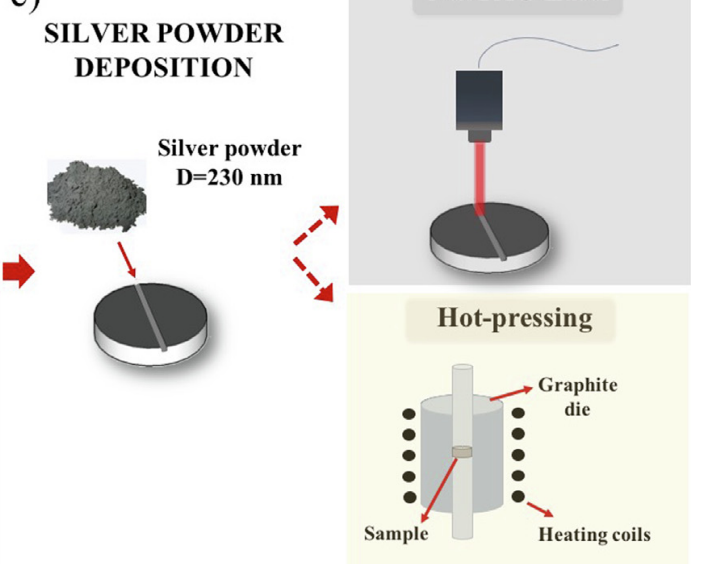

d) SILVER POWDER MELTING

Nd:YAG Laser

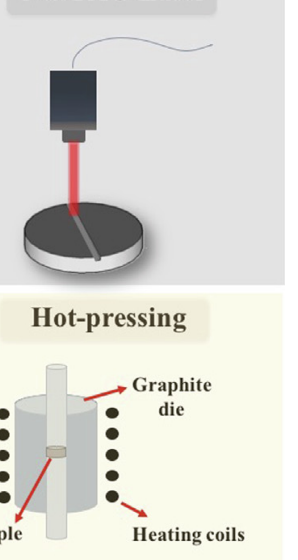

Fig. 3. Experimental set up. 


\subsection{Silver powder deposition}

Prior to the silver (Ag) wire printing, silver powder ( $\geq 99 \%$ pure) with an average grain size of $230 \mathrm{~nm}$, from Metalor Technologies-USA, was compacted into the cavity on Ti6Al4V substrate by using a pressure of $8 \mathrm{MPa}$ to ensure the total accommodation of the powder into the cavity. The excess of the powder on the surface was removed through polishing with P800 grit SiC paper. This step is illustrated in Fig. 3c).

\subsection{Micro-wire printing}

In the silver wire printing (stage 4 of Fig. 1), two techniques were performed to consolidate the powder deposited on the micro-cavities, namely laser sintering (LS) and hot-pressing (HP). Laser sintering was performed by a Nd:YAG (Sisma - $1064 \mathrm{~nm}$ of wavelength) with a spot size of $0.3 \mathrm{~mm}$ and $40 \mathrm{~W}$ of power. An energy of 10 Joules was used in all the samples. This value of energy was chosen as the best condition to melt the powder with less defects after several parameters' tests. In laser sintering, when the laser beam irradiates the powder surface, it absorbs the light energy and the temperature increases, giving raise to necking, grain growth and partial or fully melting in some cases, and also eventually densification [13]. Powder melting happens when the temperature reaches the material melting temperature and the dimension of molten pool will depends to the average applied energy per volume, which can be controlled through laser power and scanning speed [14].

In the conventional method, silver wire has been prepared by hotpressing at $960^{\circ} \mathrm{C}$ under a normal pressure of 1 bar in vacuum by using a graphite die. For this, silver powder was deposited and compacted on top of the cavity of Ti6Al4V sample.

The silver wires produced were characterized by scanning electron microscope (SEM - FEI Nova 200) in order to evaluate the quality of the wire. Table 1 shows the different types of Ti6Al4V samples produced and tested in this work.

\subsection{Electrical measurements of the wires}

In order to evaluate the electrical response of the printed silver wires, the four-point probe method has been used. In this method a current is passed through the outer probes and induces a voltage in the inner voltage probes, resulting in a I $\times \mathrm{V}$ curve. The concerned analysis was undertaken with a DC voltage current source, with current ranging from $1 \mathrm{nA}$ to $1 \mathrm{~A}$ and base accuracy of $\pm 0.02 \%$. The range of the experimental applied current was set from 0.01 to $0.1 \mathrm{~A}$.

The electrical performance was evaluated by comparing the resistivity $(\rho)$ obtained by the application of Eq. (1):

$\rho=R \frac{A}{L}$

where $\rho$ is the resistivity, $R$ is the resistance measured on the wire (taken form the $V x I$ curves), $L$ is the distance between each probe (equally spaced and constant in the measurements), and $A$ is the crosssectional area of the $\mathrm{Ag}$ wire. Two assumptions were made to use Eq. (1), namely the wire was assumed to be uniform with $250 \mu \mathrm{m}$ of diameter (diameter of the micro-channels) and the wire was placed in an

Table 1

Ti6Al4V samples details.

\begin{tabular}{lll}
\hline Sample & Surface oxidation method & Wire sintering method \\
\hline ST & No oxidation & Laser \\
STLO & Laser oxidation & Laser \\
STA20 & Anodization & Laser \\
STA120 & Anodization & Laser \\
STHP & No oxidation & Hot-pressing \\
ST20HP & Anodization & Hot-pressing \\
ST120HP & Anodization & Hot-pressing \\
\hline
\end{tabular}

insulating substrate, then all the current flows through the wire.

\section{Results and discussion}

\subsection{Surface morphology of the micro-cavities}

Fig. 4 shows the scanning electron micrographs of a typical microcavity produced by laser on Ti-6Al-4V surface processed in air, showing that the micro-cavities present a width and depth around 250-300 $\mu \mathrm{m}$, as expected. The strategy used to produce the micro-cavities consists of an overlap of different wobbles' width, starting from $25 \mu \mathrm{m}$ and increasing until the desired width is reached, in this case, $250 \mu \mathrm{m}$. This strategy resulted in a round-shaped cavity, since the emitted laser energy was better distributed along the cavity. It is notable a rough surface into the cavity with flat walls.

\subsection{Oxidized surface characterization}

\subsubsection{Oxidation by anodization}

The oxidized surface from the micro-cavity production by laser was compared to the surface oxidation by anodization method. In order to evaluate the electrical insulation capacity of the anodizing oxides, two different voltages were studied, namely $20 \mathrm{~V}$ and $120 \mathrm{~V}$. The tested conditions were chosen based on other studies reported in literature, taking into account the achievement of a uniform film with no porosity and cracks-free in order to obtain great insulation properties [15-17]. The oxide phases formation was studied by XRD and the results are seen in Fig. 5a). As can be observed, the anodic film formed after anodizing at $20 \mathrm{~V}$ shows a more amorphous structure with $\alpha$-Ti peaks mostly. In contrast, when the voltage increases to $120 \mathrm{~V}$, crystalline peaks of anatase phase $\left(\mathrm{Ti}_{2} \mathrm{O}\right)$ were detected, in agreement with other reports [18].

The crystalline transformation is closely related to the dielectric rupture of the film during anodizing process and, at low voltages, the anodic oxide film is amorphous. By increasing the voltage, the film structure changes from amorphous to crystalline. Besides the anatase phase signature, peaks of $\alpha-\mathrm{Ti}, \mathrm{Ti}_{2} \mathrm{O}_{3}$ and $\mathrm{TiO}$ were also detected at $120 \mathrm{~V}$. These phases have been reported by others works, in which phosphoric acid has been used $[17,19]$. According to literature, in the synthesis of $\mathrm{TiO}_{2}$ films in pure titanium, by various methods, the initial crystalline $\mathrm{TiO}_{2}$ phase formed is generally anatase [20,21]. In the present study the oxide formation is not in pure titanium but in Ti6Al4V, however anatase also becomes the dominant phase. The reason for the growth of anatase in Ti6Al4V is not yet understood, but it is unlikely that this is due to the presence of the alloying elements $\mathrm{V}$ and Al. Actually, aluminum tends to favor the rutile phase by creation of oxygen, and vanadium rather promotes the transformation of anatase to rutile in bulk titania, lowering the transition temperature [22].

In anodizing process, the surface of a metal is transformed into an oxide layer, through the passage of electric current, in which this layer formed anodically is allowed to dye in many different shades. In addition to the phenomenon of light interference, the coloring may be related to the crystalline structure of the film. The morphology of the surface and the thickness of the oxide layer depend on the method applied for the formation of the oxide layer and the relation between color and thickness of the oxide depends on the anodization process and the nature of the electrolyte [23].

The morphology of the anodic films produced by using 20 and $120 \mathrm{~V}$ during $1 \mathrm{~min}$ is presented in Fig. 6, where two regions are presented, a non-anodized region and an anodized region of the same sample. The $\alpha$ and $\beta$-Ti phase can be distinguished on the surface of both conditions presented. According to literature, the anodic films are composed by two layers: the inner Ti-oxide, which is composed by anatase crystals and the outer Ti-oxide formed at the film/electrolyte interface, which is composed by an amorphous oxide. During the anodization of $\mathrm{Ti}$, an amorphous-crystalline transition is involved and at relative low 

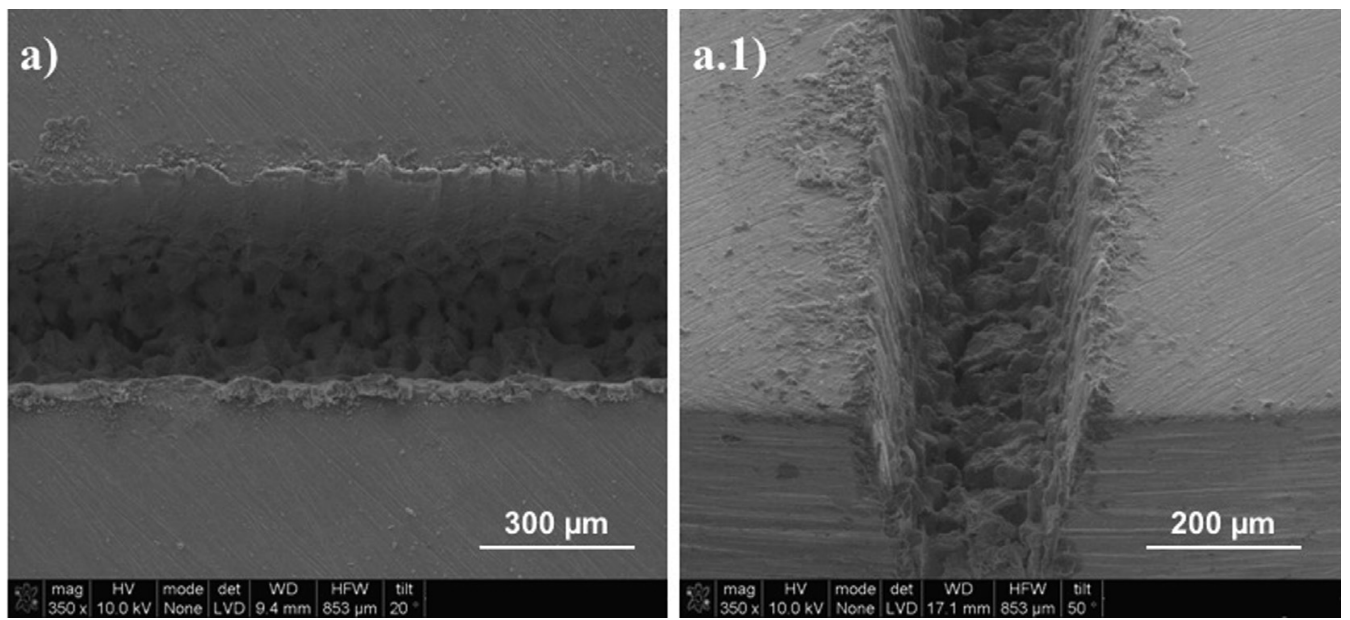

Fig. 4. SEM micrographs of the micro-cavity created by Nd:YAG laser. Scale bar in (a) is $300 \mu \mathrm{m}$ and in (a.1) is $200 \mu \mathrm{m}$.

voltages, this transition might not be completed, resulting in an amorphous and thinner oxide layer [24]. As can be observed (Fig. 6b), the anodic oxide film formed is more pronounced at the $120 \mathrm{~V}$ condition, since the thickness is higher when compared to $20 \mathrm{~V}$ (Fig. 6a). In addition, the film seems to be uniform and continuous in the case of $20 \mathrm{~V}$ and some defects (porous/impurities) in the $120 \mathrm{~V}$ condition (Fig. 6a.1 and b.1) is presented. Similar morphology was already obtained by other works, wherein phosphoric acid $\left(\mathrm{H}_{3} \mathrm{PO}_{4}\right)$ in low concentration has been used $[15,25]$. The anodizing curve (current vs time) of each condition is also presented in Fig. 6 .

In order to determine the thickness of each anodizing condition, atomic force microscope (AFM) was performed. AFM images are presented in Fig. 7. The thickness was measured after obtaining an AFM image from the region of the interface between non-anodized surface (A in the Fig. 7a) and $\mathrm{TiO}_{2}$ film (B in the Fig. 7b). A line was traced from the region $A$ to $B$ and the thickness of the film is a result of the difference in the height of these regions. The film produced with the lowest voltage $(20 \mathrm{~V})$ resulted in a thickness around $20 \mathrm{~nm}$ and the film produced by using $120 \mathrm{~V}$ presented a thickness of $152 \mathrm{~nm}$. These values of thickness are in agreement with some works in literature $[15,16]$.

\subsubsection{Oxidation by laser}

During the laser scanning, the samples are superficially melted, by the laser beam, leading to oxygen diffusion through the molten material and, thus, to its surface oxidation. The diffractograms of untreated Ti6Al4V and of the oxidized surfaces after laser scanning are shown in Fig. 5b. The peaks presented in the diffractograms reveal the presence

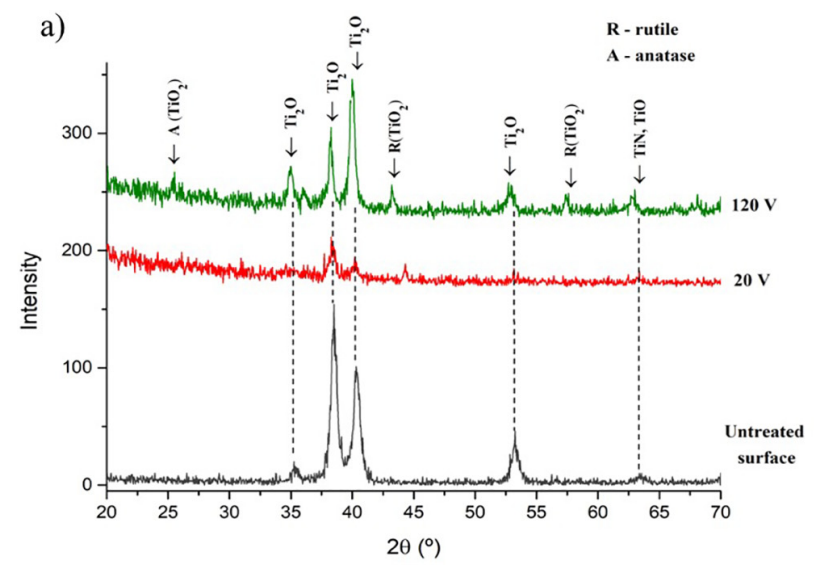

of $\alpha$-Ti, TiO and $\mathrm{Ti}_{2} \mathrm{O}_{3}$ phases, being $\alpha$-Ti the main phase formed [26-28]. No peaks of $\mathrm{TiO}_{2}$ (anatase/rutile) is visible. These sub-stoichiometric phases formation has been shown in other studies, in which titanium alloy surface was oxidized by using laser [26,29]. The formation of $\alpha$-Ti is discussed in literature [30], which consists in an interstitial solid solution $\mathrm{Ti}(\mathrm{O})$ that forms a thick oxygen-rich metallic layer under the main oxide layer on titanium alloy surface [31]. The thickness of the Ti-oxide layer can be seen in the SEM images shown in Fig. 8. The Ti-oxide layer has a thickness around $916 \mathrm{~nm}$ and the layer cross-section show a dense and rough oxide film without pores on the surface.

\subsection{Silver powder sintering - wire printing}

After micro-cavity creation and insulation layer production on the surface, silver powder was deposited and accommodated into the cavities. Then, silver powder was sintered by using two methodologies, namely hot-pressing and laser sintering. Fig. 9 presents SEM images of the silver wires after sintering, in which Fig. 9(a) corresponds to the wire sintered by laser at average power of $4 \mathrm{~W}$ and Fig. 9(b) presents the wire after sintering by hot-pressing. As can be observed the silver powder grains were apparently melted and spread to completely merge together with neighboring grains in both sintering conditions. However, the wire sintered by laser presents more imperfections on the surface. The contraction of the silver powder after sintering is more evident in this condition.

Compared to heating with furnace, the laser sintering provides the

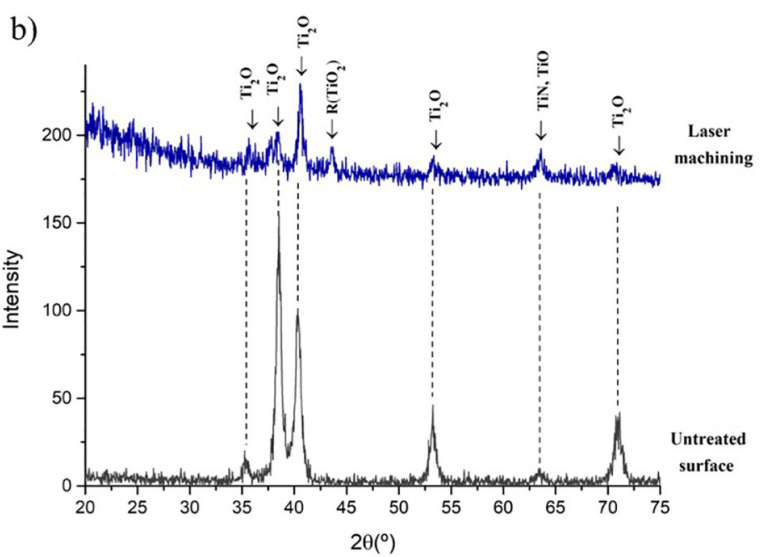

Fig. 5. XRD patterns of untreated Ti6Al4V alloy and samples with oxidized surface by: (a) anodization at $20 \mathrm{~V}$ and $120 \mathrm{~V}$ during 1 min and (b) laser scanning. 

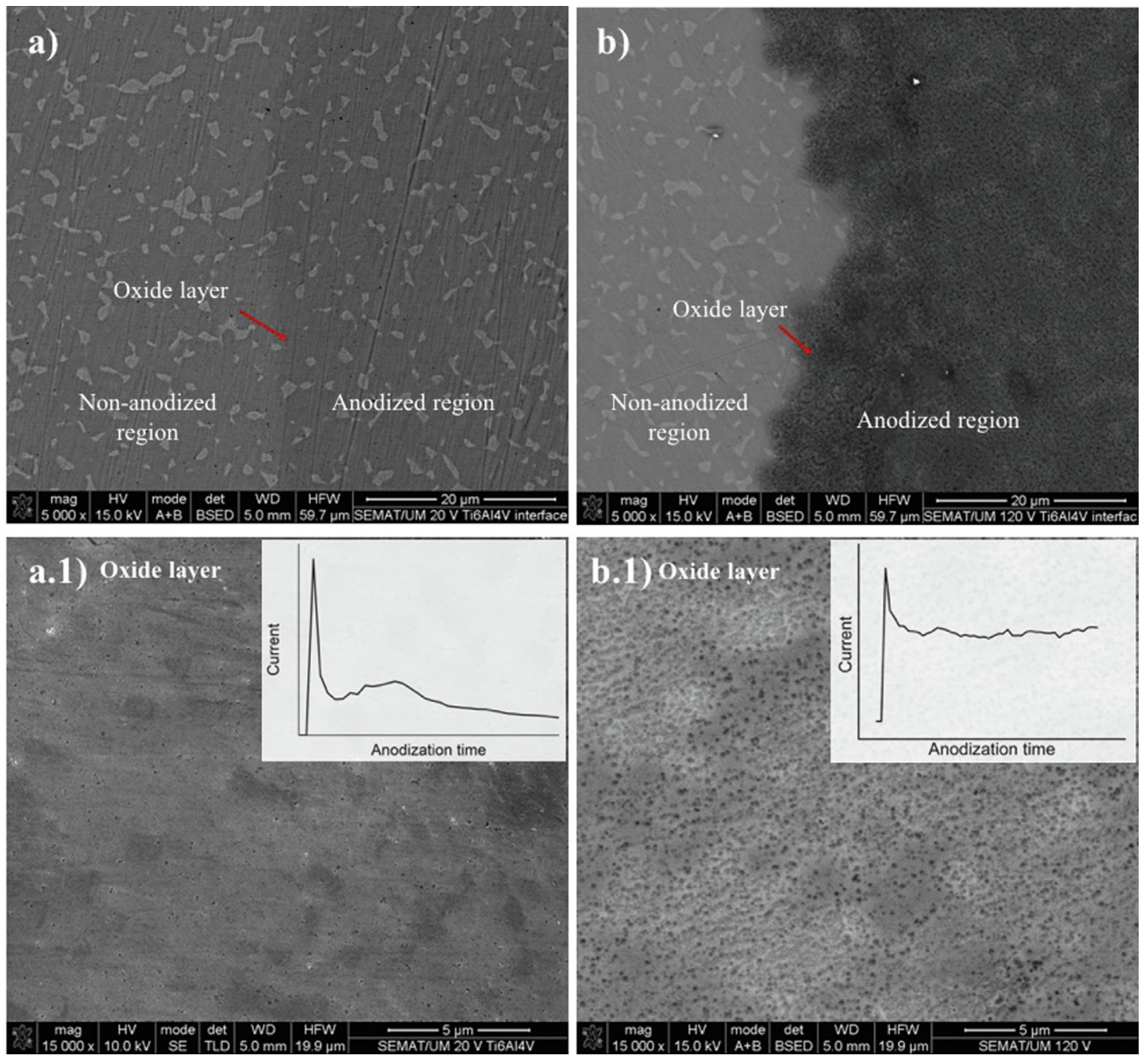

Fig. 6. SEM micrographs of Ti6Al4V surface after anodizing at $20 \mathrm{~V}$ (a) and $120 \mathrm{~V}$ (b). The interface between two regions (anodized and non-anodized) is presented. Images (a.1) and (b.1) show the zone of the oxide layer and their correspondents anodization curves for 20 and $120 \mathrm{~V}$, respectively.

advantage of localized energy deposition, in which the powder is selectively irradiated and locally sintered, while the non-irradiated parts stays unconsolidated [32], as occurred in our case. Fig. 10 shows the process principle of laser sintering and it is possible to see in the extended SEM micrograph some region with non-consolidated particles. The main issue about laser sintering is related to a very steep temperature gradient that is generated due to the fast heating and cooling rate during the process. The temperature gradient induced surface tension in the molten pool can lead to convective motions (Marangoni effect) and also induce high internal stresses [33]. As can be seen in Fig. 10, when the laser irradiates the top surface, the expansion of the heated layer is restricted by the surrounding area, which generates a compressive stress on the top surface. In contrast, the extent to which the laser moves away, the contraction of the top layer is restricted by

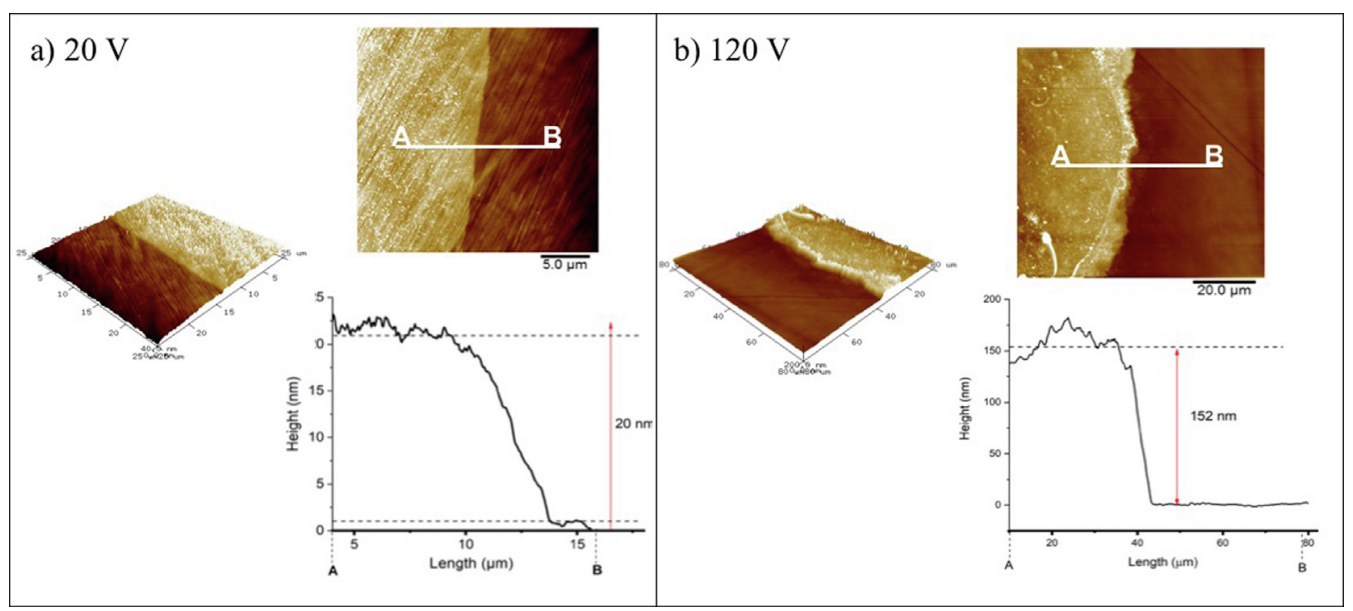

Fig. 7. AFM images of anodic titanium oxide on Ti6Al4V surface: (a) $20 \mathrm{~V}$ and (b) $120 \mathrm{~V}$. 


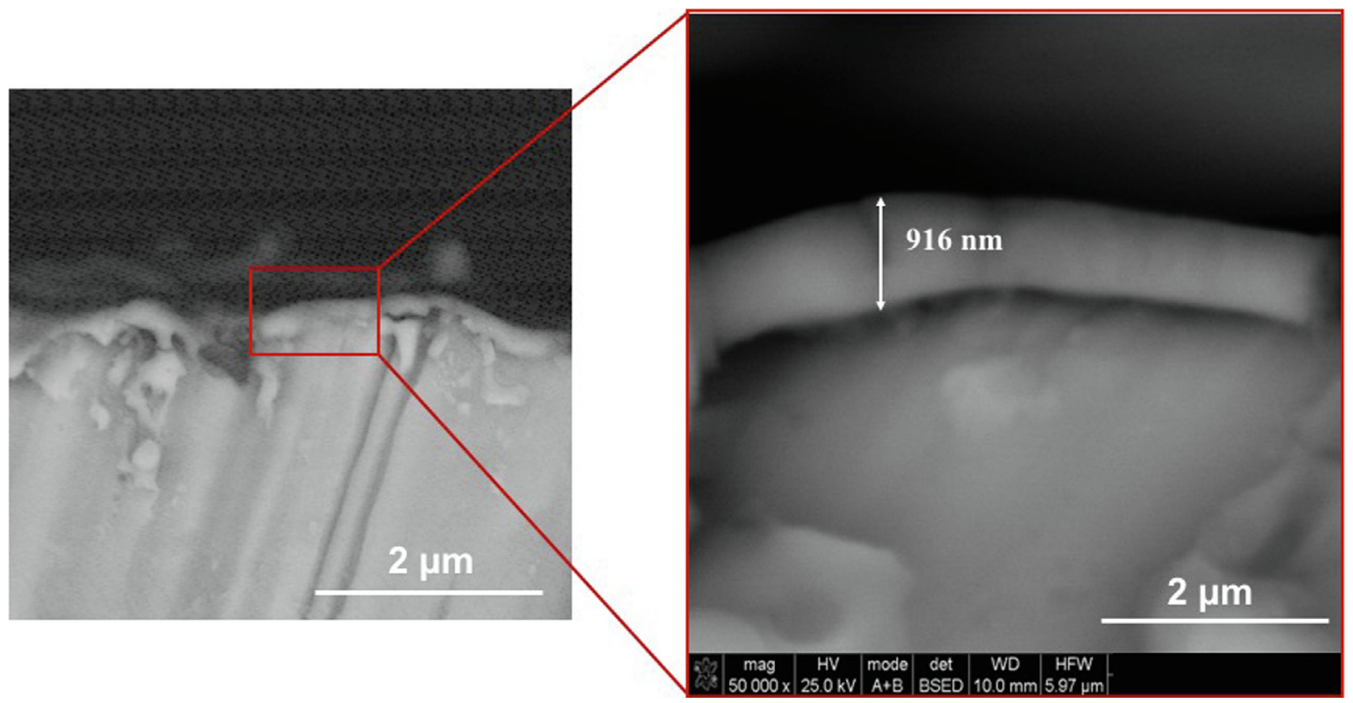

Fig. 8. Cross-section micrograph of Ti6Al4V surface oxidized by laser micro-scanning.

the surrounding area, leading to a tensile residual stress on the top surface. This residual stress will accumulate during the laser scan, which can result in delamination and cracks formation [14]. As can be seen on Fig. 10, there are some deficiency of molten material on the surface as a result of stress concentration by laser process. This issue has already mentioned by other works [34].

As regards hot-pressing system, a combination of pressure and temperature is responsible for a particular density at a lower temperature than would be require for sintering alone and at lower pressure. The effect of the lower temperature is that the grain growth can be avoided [35]. The sintering mechanism consists in, firstly, particles in contact and necks formation; the necks grow, and open porosity starts to decrease. Finally, necks become quite large, pores spheroidize and all open porosity disappears, the densification occurs [36]. The great advantage of sintering by HP is that there is time available for all sintering mechanisms to occur, unlike the process by LS.

\subsection{Electrical measurements of printed wires}

In order to evaluate the electrical insulation capacity of the oxide layer formed by both laser texture and anodizing on titanium alloy surface, electrical measurements were performed. For this purpose, the four-point probe method has been used by applying an electrical current and measuring the voltage resultant. A scheme of the setup of the measurement is shown in Fig. 11 jointly to a VxI curves of the studied samples, showing the range of electrical current applied.

In Table 2 are presented the experimental electrical resistance (Ohms) obtained by the VxI curves. In order to compare the results, the electrical resistance of the wire printed in an insulator substrate (zirconia disk) was performed as also the electrical resistance of the
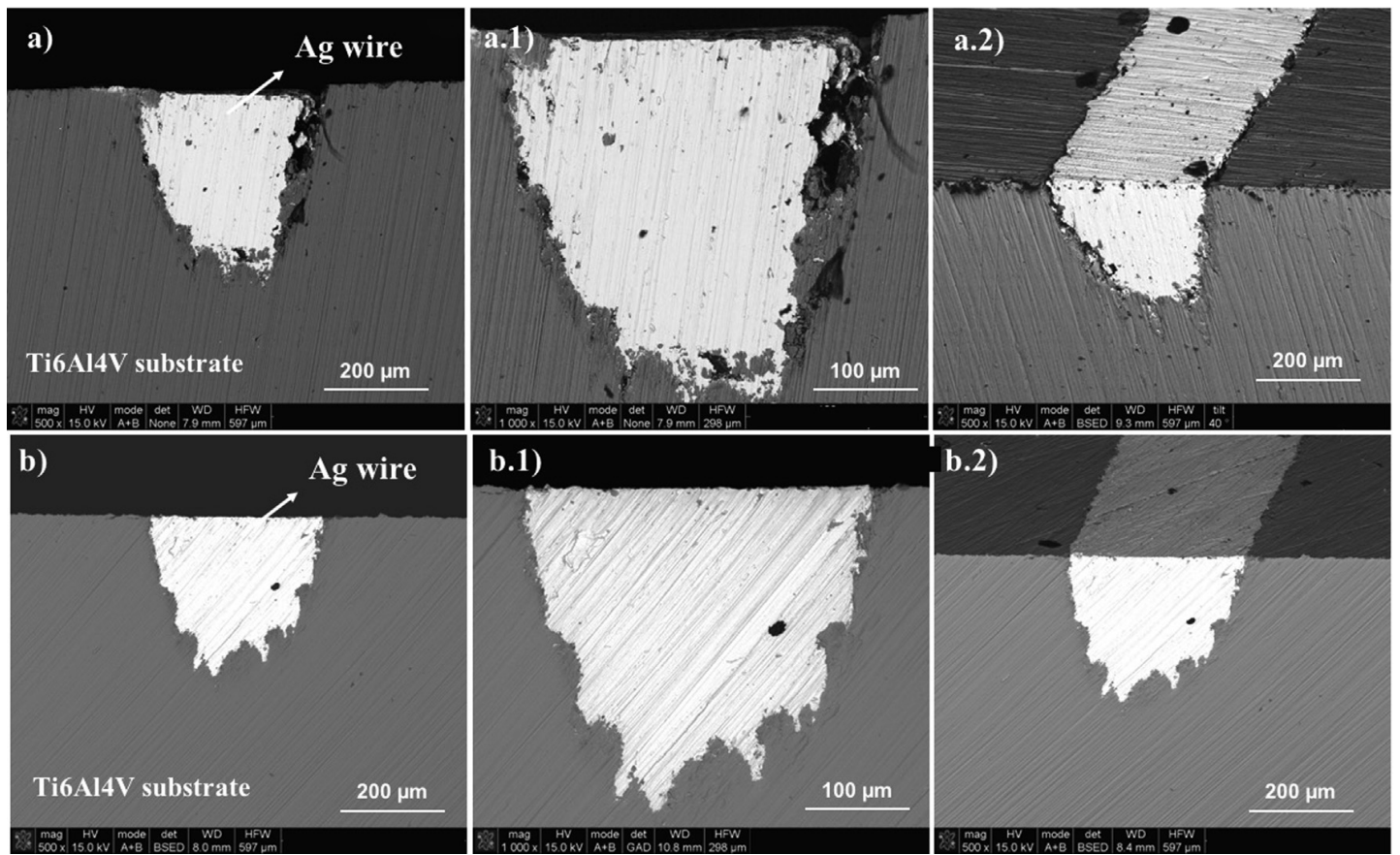

Fig. 9. Silver wires printed on Ti6Al4V through sintering of the powder by: (a) Laser and (b) Hot-pressing. 


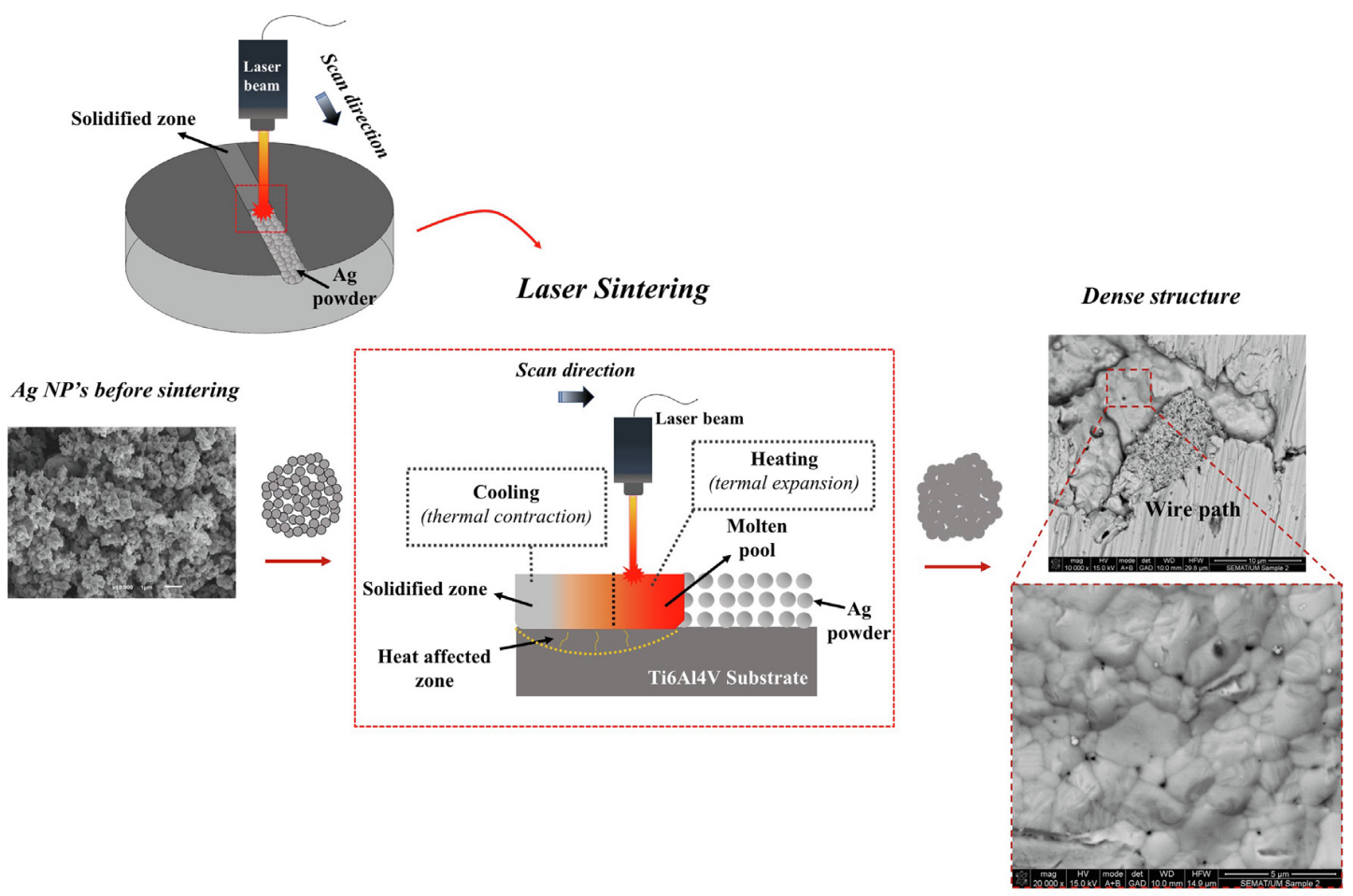

Fig. 10. Schematic description of laser sintering of the silver wire on the Ti6Al4V substrate.

Ti6Al4V substrate. The electrical resistivity values of the Ti6Al4V titanium alloy and silver according to literature are presented in Table 3.

Several works in literature have reported the calculation of resistivity in cases of multilayers film, but they are composed by oxidemetal-oxide multilayer, in which the resistance of the multilayer is approximately equal to the parallel resistance of the metal and oxide layers. Since the conductivity of the metal layer is about 100 times higher than that of oxide layer, the conductivity of the multilayer is mainly supplied by the metal layer present [37-39]. However, studies concerning the resistivity calculation of metal on metal substrate separated by a thin oxide layer are scarce and there is no specific equation for that. As already known in literature, $\mathrm{TiO}_{2}$ is electrically insulating with an extremely high resistivity above $10^{6} \Omega \cdot \mathrm{m}$, but the suboxidized $\mathrm{TiO}_{2}$ with an excess of titanium is an n-type semiconductor, indicating that the defect disorder and the O/Ti stochiometry play an important
Table 2

Resistance values calculated for each condition.

\begin{tabular}{ll}
\hline Sample & $\mathrm{R}(\Omega)$ \\
\hline ST & 0.0038 \\
STLO & 0.0131 \\
STA20 & 0.0179 \\
STA120 & 0.0049 \\
STHP & 0.0008 \\
ST20HP & 0.0004 \\
ST120HP & 0.0003 \\
Ti6A14V substrate & $\mathbf{0 . 0 0 0 3}$ \\
Wire in ZrO2 substrate & $\mathbf{0 . 0 1 3 5}$
\end{tabular}
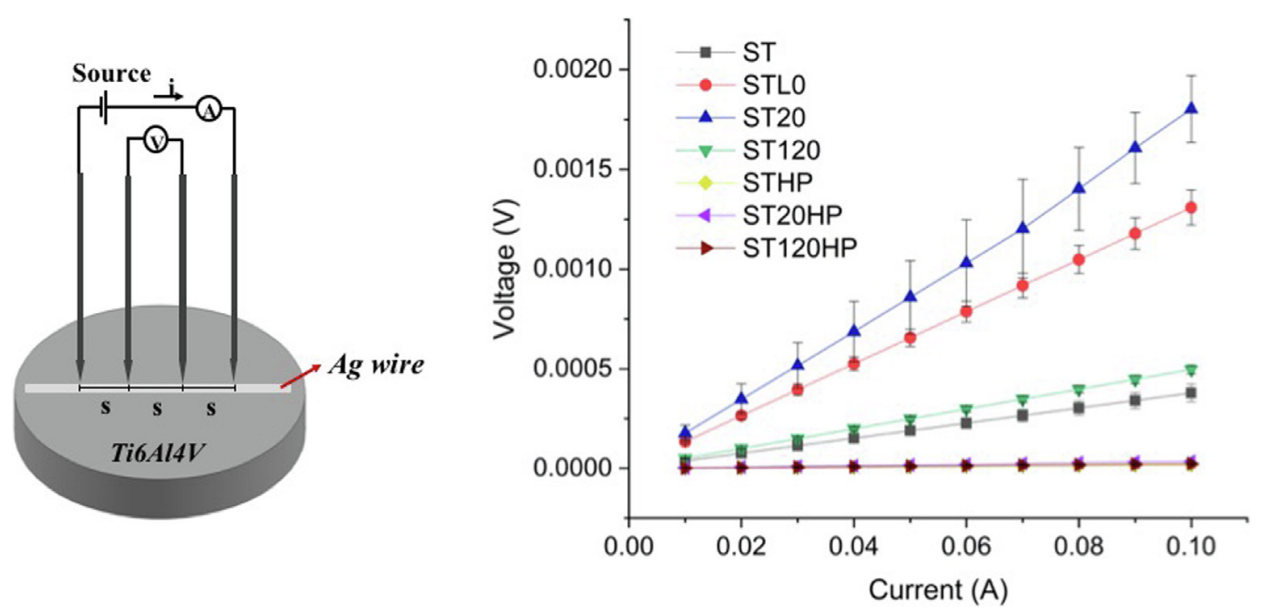

Fig. 11. Arrangement for resistivity measurements by using four-probe method and VxI curves of the conditions studied. The letter s represents the distance between the probes, which must be known. 
Table 3

Electrical resistivity of the materials according to literature.

\begin{tabular}{ll}
\hline Material & Electrical resistivity $(\Omega \cdot \mathrm{m})$ \\
\hline Ti6Al4V & $1.71 \times 10^{-6}[41]$ \\
Silver & $1.60 \times 10^{-8}[42]$ \\
\hline
\end{tabular}

role in the electrical properties of $\mathrm{TiO}_{2}$ [40].

According to the results, there are two factors that may influence the resistance values, namely: the wire quality, and the insulator layer efficiency. The wire quality includes the impurities and imperfections which is a result of the sintering process and may further decrease the mean free path of electrons. As regard the insulator layer, its efficiency will depend not only its thickness, but also its morphology and structure formed.

The electrical resistance measured in the samples has two opposites trends depending on the sintering method: it slightly decreases as the insulating increases in HP group, from 0.0008 to $0.0003 \Omega$ and it increases in LS approach, as the insulator layer was improved (from 0.0038 to $0.0179 \Omega$ ). Nonetheless, when the resistance measured in the Ti6Al4V is compared with the resistance values of the HP group, the values are close. This suggests that when hot-pressing is used, although the densification is satisfactory, the interface between the silver wire and titanium alloy substrate is damaged, decreasing the contact resistance, which will force the current to flow through the substrate rather than the wire.

On the other hand, by analyzing the LS group, the values of the electrical resistance increase as the insulation layer is improved, from ST to STLO and STA20, except the sample STA120, in which the electrical resistance value decreased to $0.0049 \Omega$. This behavior can be justified through the oxide layer morphology formed at $120 \mathrm{~V}$, which can be seen in Fig. 6 a.2 as well as in anodizing curve. The oxide layer at $120 \mathrm{~V}$ presents a great defects distribution in contrast with the oxide formed at $20 \mathrm{~V}$, although in this condition the oxide thickness is considerably lower. In addition, the current-time behavior measured during the potentiostatic preparation of oxide layer reflects this overall mechanism (Fig. 6a.1 and b.1), in which for $20 \mathrm{~V}$ condition, in the first stage, the current increases due to the oxide layer formation and then decreases rapidly reaching zero, as a consequence of increasing resistance of the rapidly growing oxide layer. In contrast, the anodizing curve for $120 \mathrm{~V}$ condition shows that after the oxide formation the current decreases but not in total, keeping constant until the end of the process [43-45].

In terms of laser sintering process, the obtained larger grains size may have influenced the electrical resistivity of the wire. In the case of LS, the energy is deposited in a very thin/fine surface layer of the single grains that will melt partially. Then, neighboring grains will join by the liquid surface layer that re-solidifies very quickly and consequently, the grains are frozen. As a consequence of that a low grain boundary is generated, favoring the grains connectivity, affecting positively the current flow [46-48].

Taking into account the electrical resistance measured on the wire deposited and sintered by laser in zirconia substrate, in which all the current flows to the metallic part (wire), a value of resistivity can be calculated through Eq. (1), presented in Section 2. In this case, according to Equation, $A$ is the cross-section area of the wire, $\mathrm{L}$ is the probe distance $(0.001 \mathrm{~m})$ and $\mathrm{R}$ is the resistance of the wire, wire, taken from the VxI curve. Thus, a value of $4.86 \times 10^{-7} \Omega \cdot \mathrm{m}$ was found, which is still far from the known value for silver $\left(1.6 \times 10^{-8} \Omega \cdot \mathrm{m}\right)$ [42].

To verify the experimentally calculated value for the silver wire resistivity, numerical simulations were performed using the COMSOL Multiphysics software and using the main parameters shown in Table 4. The electric current from the AC/DC model was used for the numerical simulations. Four geometric points (P1, P2, P3, and P4) were place on top of the silver wire with $1 \mathrm{~mm}$ distance between each other, in order to simulate the four point probes (Fig. 12a). The silver wire is perfectly isolated from the substrate. At the furthest points (P1 and P4) a current source of $0.2 \mathrm{~A}$ and $-0.2 \mathrm{~A}$ was applied. A wide range of resistivity values were attributed to the silver wire and the voltage output for each resistivity was measured between $\mathrm{P} 2$ and P3.

The electric potential value measured experimentally for a $0.2 \mathrm{~A}$ of applied current in the silver wire was $0.27 \mathrm{mV}$. From the simulation, an electric potential value of $0.277 \mathrm{mV}$ between P2 and P3 is obtained for a silver resistivity of $5 \times 10^{-7} \Omega \cdot \mathrm{m}$, which is in good agreements with the expected theoretical value. Fig. $12 \mathrm{~b}$ shows the distribution of the electric potential along the wire for a silver resistivity of $5 \times 10^{-7} \Omega \cdot \mathrm{m}$.

\section{Conclusions}

Print of micro communication systems in titanium alloy (Ti-6Al-4 V) surface assisted by laser is presented in this work. In this context, microcavities were successfully produced by laser scanning and silver powder has been consolidated into the cavities, forming micro-wires. Thin oxide layers by different approaches have been produced and tested regarding their insulation performance, in order to minimize the loss of electrical current to the substrate.

In summary, the micro-wires produced by laser technology presented low electrical resistance values, from 0.0038 to $0.0179 \Omega$, comparable with the wire printed on the zirconia substrate (resistance of the wire $-0.0135 \Omega$ ). This behavior can be attributed to a greater wire contribution for the current flow, with the exception of the condition ST120, in which the resistance value decreased to 0.0049, as a consequence of defects on the insulator film. As regards HP groups, although HP sintering presented a satisfactory densification of the wire, the resistance measured values were very close to the resistance values of the Ti6Al4V substrate. These results indicated a weak contribution of the wire to the current flow, due to the low contact resistance in the interface between the materials (Ti6Al4V and silver), as a result of the pressure and temperature used in this method.

Therefore, this work presented a hybrid approach for printing micro-wires in metal substrate through laser technology as also showed different methods to insulate the wire from the substrate, allowing its great efficiency in the current flow.

\section{CRediT authorship contribution statement}

C.G. Moura: Conceptualization, Methodology, Validation, Investigation, Writing - original draft, Writing - review \& editing. $\mathbf{O}$. Carvalho: Supervision, Software. V.H. Magalhaes: Methodology, Writing - review \& editing. R.S.F. Pereira: Methodology, Validation. M.F. Cerqueira: Resources, Writing - review \& editing. L.M.V. Gonçalves: Resources, Writing - review \& editing. R.M. Nascimento: Supervision. F.S. Silva: Supervision, Project administration, Resources.

\section{Declaration of Competing Interest}

The authors declare that they have no known competing financial interests or personal relationships that could have appeared to influence the work reported in this paper.

\section{Acknowledgement}

This work has been supported by FCT (Fundação para a Ciência e Tecnologia -Portugal) in the scope of the projects UID/EEA/04436/ 2019 and NORTE-01-0145-FEDER-000018-HAMaBICo and Add.Additive_Manufacturing to Portuguese Industry_POCI-01-0247FEDER-024533. I wish to thank the CNPq (205791/2014-0). 
Table 4

Numerical simulation parameters.

\begin{tabular}{|c|c|}
\hline Module & $\mathrm{AC} / \mathrm{DC}$ \\
\hline Method & Finite Element Method (FEM) \\
\hline Equations Solved & $\begin{array}{l}J=\sigma E+J_{e}-\nabla\left(\sigma \nabla V-J_{e}\right)=Q_{j} \text { where } \sigma \text { is the electrical conductivity (SI units: } \mathrm{S} / \mathrm{m} \text { ), } J_{e} \text { is an externally generated current density (SI } \\
\left.\text { units: } \mathrm{A} / \mathrm{m}^{2}\right) \text { and } Q_{j} \text { is a current source (SI units: A) }\end{array}$ \\
\hline Study & Stationary \\
\hline Computational Mesh & 3D mesh with triangular and tetrahedral elements (COMSOL physics controlled mesh) \\
\hline Refinement of the Computational Mesh & Extremely fine (with $0.16 \mathrm{~mm}$ as maximum element size and $1.6 \mu \mathrm{m}$ as minimum element size) \\
\hline Convergence Criteria & Stationary iterative solver Multigrid with a relative tolerance of $1 \times 10^{-7}$ \\
\hline Boundary Conditions & All surfaces were electrically isolated. At the furthest points (P1 and P4) a current source of $0.2 \mathrm{~A}$ and $-0.2 \mathrm{~A}$ was applied. \\
\hline Output Results & Electrical potential measured between the geometric points P2 and P3 for a wide range of resistivity values for the silver wire. \\
\hline
\end{tabular}
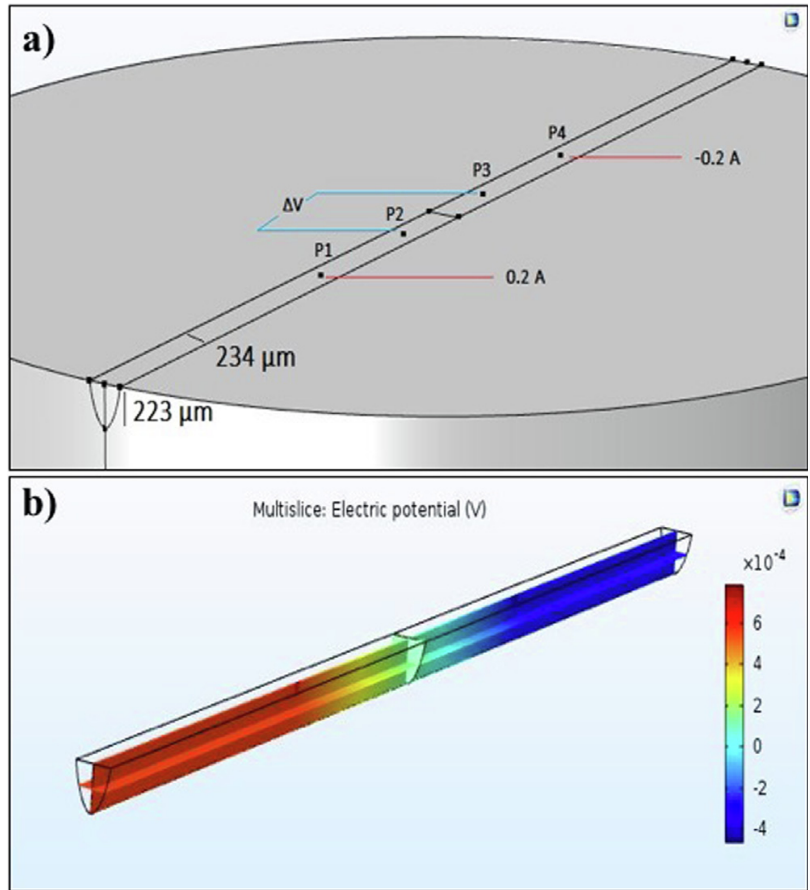

Fig. 12. (a) Draft of the geometric configuration of the simulation conditions, (b) Distribution of the electric potential along the silver wire.

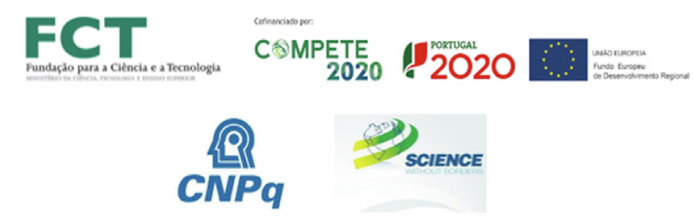

\section{References}

[1] V.Y. Zadorozhnyy, E.V. Kaevitser, A.N. Kopylov, Y.V. Borisova, V.V. Sudarchikov, R.S. Khasenova, M.V. Gorshenkov, M.Y. Zadorozhnyy, S.D. Kaloshkin, Synthesis of the hydroxyapatite coatings on the Ti substrates by mechanical alloying, Surf. Coatings Technol. 281 (2015) 157-163, https://doi.org/10.1016/j.surfcoat.2015. 09.056.

[2] E. Mohseni, E. Zalnezhad, A.R. Bushroa, Comparative investigation on the adhesion of hydroxyapatite coating on Ti-6Al-4V implant: a review paper, Int. J. Adhes. Adhes. 48 (2014) 238-257, https://doi.org/10.1016/j.ijadhadh.2013.09.030.

[3] G.M. Fatih Toptan, Alexandra C. Alves, Oscar Carvalho, Flavio Bartolomeu, Ana M.P. Pinto, Filipe Silva, Corrosion and tribocorrosion behaviour of Ti6Al4V produced by selective laser melting and hot pressing in comparison with the commercial alloy, J. Mater. Process. Technol. (2018), https://doi.org/10.1016/j. jmatprotec.2018.11.008.

[4] L. Tiainen, P. Abreu, M. Buciumeanu, F. Silva, M. Gasik, Novel laser surface texturing for improved primary stability of titanium implants, J. Mech. Behav. Biomed. Mater. (2019).

[5] G. Miranda, F. Sousa, M.M. Costa, F. Bartolomeu, F.S. Silva, O. Carvalho, Surface design using laser technology for Ti6Al4V-hydroxyapatite implants, Opt. Laser
Technol. 109 (2019) 488-495, https://doi.org/10.1016/j.optlastec.2018.08.034.

[6] D. Faria, C.S. Abreu, M. Buciumeanu, N. Dourado, O. Carvalho, F.S. Silva, G. Miranda, Ti6Al4V laser surface preparation and functionalization using hydroxyapatite for biomedical applications, J. Biomed. Mater. Res. - Part B Appl. Biomater. 106 (2018) 1534-1545, https://doi.org/10.1002/jbm.b.33964.

[7] F. Bartolomeu, M. Buciumeanu, M.M. Costa, N. Alves, M. Gasik, F.S. Silva, G. Miranda, Multi-material Ti6Al4V \& PEEK cellular structures produced by SelectiveLaser Melting and Hot Pressing: A tribocorrosion study targeting orthopedic application, J. Mech. Behav. Biomed. Mater. 89 (2019) 54-64.

[8] J. Andreu-Perez, D.R. Leff, H.M.D. Ip, G.Z. Yang, From wearable sensors to smart implants-toward pervasive and personalized healthcare, IEEE Trans. Biomed. Eng. 62 (2015) 2750-2762, https://doi.org/10.1109/TBME.2015.2422751.

[9] E.H. Ledet, B. Liddle, K. Kradinova, S. Harper, Smart implants in orthopedic surgery, improving patient outcomes: a review, Innovation Entrepreneurship Health 5 (2018) 41.

[10] C.O. Connor, A. Kiourti, Wireless sensors for smart orthopedic implants, J. BioTribo-Corrosion (2017) 1-8, https://doi.org/10.1007/s40735-017-0078-z.

[11] A. Kiourti, K.A. Psathas, K.S. Nikita, Implantable and ingestible medical devices with wireless telemetry functionalities: a review of current status and challenges, Bioelectromagnetics 15 (2014), https://doi.org/10.1002/bem.21813.

[12] C.G. Moura, O. Carvalho, L.M.V. Gonçalves, M.F. Cerqueira, R. Nascimento, F. Silva, Laser surface texturing of Ti-6Al-4V by nanosecond laser: Surface characterization, Ti-oxide layer analysis and its electrical insulation performance, Mater. Sci. Eng., C (2019).

[13] J.P. Kruth, P. Mercelis, J. Van Vaerenbergh, L. Froyen, M. Rombouts, Binding mechanisms in selective laser sintering and selective laser melting, Rapid Prototyping J. (2005), https://doi.org/10.1108/13552540510573365.

[14] C.H. Fu, Y.B. Guo, Three-dimensional temperature gradient mechanism in selective laser melting of Ti-6Al-4V, J. Manuf. Sci. Eng. 136 (2014) 1-8, https://doi.org/10. $1115 / 1.4028539$.

[15] N.K. Kuromoto, R.A. Simão, G.A. Soares, Titanium oxide films produced on commercially pure titanium by anodic oxidation with different voltages, Mater. Charact. 58 (2007) 114-121, https://doi.org/10.1016/j.matchar.2006.03.020.

[16] A. Karambakhsh, A. Afshar, P. Malekinejad, Corrosion resistance and color properties of anodized Ti-6Al-4V, J. Mater. Eng. Perform. 21 (2012) 121-127, https:// doi.org/10.1007/s11665-010-9791-1.

[17] W. Asumpinwong, K. Saengkiettiyut, V. Srimaneepong, Different constant voltages of anodization on the corrosion behavior of Ti-6Al-4V alloy, Chiang Mai J. Sci. 42 (2015) 239-248.

[18] Y.T. Sul, C.B. Johansson, Y. Jeong, K. Röser, A. Wennerberg, T. Albrektsson, Oxidized implants and their influence on the bone response, J. Mater. Sci. - Mater. Med. 12 (2001) 1025-1031.

[19] R. Narayanan, S.K. Seshadri, Phosphoric acid anodization of Ti-6Al-4V - Structural and corrosion aspects, Corros. Sci. 49 (2007) 542-558, https://doi.org/10.1016/j. corsci.2006.06.021.

[20] K. Okada, N. Yamamoto, Y. Kameshima, A. Yasumori, K.J.D. MacKenzie, Effect of silica additive on the anatase-to-rutile phase transition, J. Am. Ceram. Soc. 84 (2004) 1591-1596, https://doi.org/10.1111/j.1151-2916.2001.tb00882.x.

[21] H. Shin, H.S. Jung, K.S. Hong, J.K. Lee, Crystal phase evolution of TiO2 nanoparticles with reaction time in acidic solutions studied via freeze-drying method, J. Solid State Chem. 178 (2005) 15-21, https://doi.org/10.1016/j.jssc.2004.09.035.

[22] M. Rinner, J. Gerlach, W. Ensinger, Formation of titanium oxide films on titanium and Ti6A14V by O 2 -plasma immersion ion implantation, Surf. Coatings Technol. 132 (2000) 111-116, https://doi.org/10.1016/S0257-8972(00)00712-X.

[23] T.A. Young-Taeg Sul, Carina B. Johansson, Yongsoo Jeong, The electrochemical oxide growth behaviour on titanium in acid and alkaline electrolytes, Med. Eng. Phys. 23 (2001) 329-346, https://doi.org/10.1021/acs.jpca.7b04442.

[24] H. Habazaki, K. Shimizu, S. Nagata, P. Skeldon, G.E. Thompson, G.C. Wood, Ionic transport in amorphous anodic titania stabilised by incorporation of silicon species, Corros. Sci. 44 (2002) 1047-1055, https://doi.org/10.1016/S0010-938X(01) Corros. Sci.

[25] Z.J. Liu, X. Zhong, J. Walton, G.E. Thompson, Anodic film growth of titanium oxide using the 3-electrode electrochemical technique : effects of oxygen evolution and morphological, Characterizations 163 (2016) 75-82, https://doi.org/10.1149/2. 0181603jes.

[26] A. Pérez Del Pino, P. Serra, J.L. Morenza, Coloring of titanium by pulsed laser processing in air, Thin Solid Films 415 (2002) 201-205, https://doi.org/10.1016/ S0040-6090(02)00632-6. 
[27] A. Pérez Del Pino, P. Serra, J.L. Morenza, Oxidation of titanium through Nd:YAG laser irradiation, Appl. Surf. Sci. 197-198 (2002) 887-890, https://doi.org/10. 1016/S0169-4332(02)00447-6.

[28] A.J. Antończak, Ł. Skowroński, M. Trzcinski, V.V. Kinzhybalo, Ł.K. Łazarek, K.M. Abramski, Laser-induced oxidation of titanium substrate: Analysis of the K.M. Abramski, Laser-induced oxidation of titanium substrate: Analysis of the
physicochemical structure of the surface and sub-surface layers, Appl. Surf. Sci. 325 (2015) 217-226, https://doi.org/10.1016/j.apsusc.2014.11.062.

[29] A. Pérez del Pino, J.M. Fernández-Pradas, P. Serra, J.L. Morenza, Coloring of titanium through laser oxidation: comparative study with anodizing, Surf. Coatings Technol. 187 (2004) 106-112, https://doi.org/10.1016/j.surfcoat.2004.02.001.

[30] G.Z. Chen, D.J. Fray, T.W. Farthing, Cathodic deoxygenation of the alpha case on titanium and alloys in molten calcium chloride, Metall. Mater. Trans. B Process Metall. Mater. Process. Sci. 32 (2001) 1041-1052, https://doi.org/10.1007/, s11663-001-0093-8.

[31] H. Dong, X.Y. Li, Oxygen boost diffusion for the deep-case hardening of titanium alloys, Mater. Sci. Eng., A 280 (2000) 303-310, https://doi.org/10.1016/S09215093(99)00697-8.

[32] P. Fischer, V. Romano, A. Blatter, H.P. Weber, Highly precise pulsed selective laser sintering of metallic powders Nd: YAG, Laser Phys. Lett. 55 (2005) 48-55, https:// doi.org/10.1002/lapl.200410118.

[33] T.D. Bennett, D.J. Krajnovich, C.P. Grigoropoulos, P.P. Baumgart, Mechanism in pulsed laser texturing of magnetic disk substrates, ASME. J. Heat Transf. 119 (1997) 589-596, https://doi.org/10.1115/1.2824146.

[34] V.S. Sufiiarov, A.A. Popovich, E.V. Borisov, I.A. Polozov, D.V. Masaylo, The effect of layer thickness at selective laser melting, Procedia Eng. 174 (2017) 126-134, https://doi.org/10.1016/j.proeng.2017.01.179.

[35] M. Basaran, T.Z. Kattamis, M. Basaran, T.Z. Kattamis, R. Mehrabian, M.C. Flemings, Metall. Trans. 4 (1973) 2429-2434.

[36] H.V. Atkinson, S. Davies, Fundamental aspects of hot isostatic pressing: an overview, Metallurg. Mater. Trans. A. (2000).

[37] J.-J.C. Yi-Cheng Lin, Lu Kun-Hsin, Characterization the electrical and optical properties of AZO/AgPd/AZO multilayer film using RF magnetron sputtering, Chinese J. Phys. (2016) 1-9, https://doi.org/10.1016/j.cjph.2016.06.007.
[38] B.L. Nai-fei Ren, Li-jing Huang, Ming Zhou, Introduction of Ag nanoparticles and AZO layer to prepare AZO/Ag/FTO trilayer films with high overall photoelectric properties, Ceram. Int. (2014) 1-8, https://doi.org/10.1016/j.ceramint.2014.01. 087.

[39] T.C. Lin, W.C. Huang, F.C. Tsai, The structural and electro-optical characteristics of $\mathrm{AZO} / \mathrm{Cr}: \mathrm{Cu} / \mathrm{AZO}$ transparent conductive film, Thin Solid Films 11 (2015) 1-6, https://doi.org/10.1016/j.tsf.2015.06.011.

[40] J. Nowotny, T. Bak, M.K. Nowotny, L.R. Sheppard, Titanium dioxide for solar-hydrogen II. Defect chemistry, Int. J. Hydrogen Energy 32 (2007) 2630-2643, https:// doi.org/10.1016/j.ijhydene.2006.09.005.

[41] E.G.L. Bolzoni, E.M. Ruiz-Navas, Flexural properties, thermal conductivity and electrical resistivityof prealloyed and master alloy addition powder metallurgy Ti-6Al-4V, Mater. Des. 52 (2013) 888-895, https://doi.org/10.1016/j.matdes. 2013.06036.

[42] R.A. Matula, Electrical resistivity of cooper, gold, palladium, and silver, J. Phys. Chem. Ref. Data (2009), https://doi.org/10.1063/1.555614.

[43] A. Ghicov, P. Schmuki, Self-ordering electrochemistry: a review on growth and functionality of $\mathrm{TiO}_{2}$ nanotubes and other self-aligned $\mathrm{MO}_{\mathrm{x}}$ structures, Chem. Commun. (2009) 2791-2808, https://doi.org/10.1039/b822726h.

[44] T. Ohgai, Magnetoresistance of nanowires electrodeposited into anodized aluminum oxide nanochannels, Nanotechnol. Nanomater. Vuko-var INTECH (2012) $101-125$.

[45] H. Yoo, M. Kim, Y.T. Kim, K. Lee, J. Choi, Catalyst-doped anodic TiO2 nanotubes: binder-free electrodes for (photo) electrochemical reactions, Catalysts 8 (11) (2018) 555.

[46] D.M.A. Yildiz, S.B. Lisesivdin, M. Kasap, Non-adiabatic small polaron hopping conduction in Nb-doped $\mathrm{TiO}_{2}$ thin film, Phys. B (2009) 10-14, https://doi.org/10. 1016/j.physb.2008.12.034

[47] D.M.A. Yildiz, S.B. Lisesivdin, M. Kasap, Electrical properties of $\mathrm{TiO}_{2}$, J. Non. Cryst. Solids. (2008) 5-9 doi:10.1016/j.

[48] H. Zhang, G. Lee, C. Gong, L. Colombo, K. Cho, Grain boundary effect on electrical transport properties of graphene, J. Phys. Chem. C. 118 (5) (2014) 2338-2343. 